Article

\title{
Anthocyanin Encapsulated by Ferulic Acid-Grafted-Maltodextrin (FA-g-MD) Microcapsules Potentially Improved its Free Radical Scavenging Capabilities Against $\mathrm{H}_{2} \mathrm{O}_{2}$-Induced Oxidative Stress
}

\author{
Yi Ma ${ }^{1, *+}{ }^{\dagger}$, Yunhui Feng ${ }^{2,+}$, Wanling Zeng ${ }^{1}$ and Huibo Luo ${ }^{1, *}$ \\ 1 College of Bioengineering, Sichuan University of Science and Engineering, Zigong 643000, China; \\ zhangyer2008@suse.edu.cn \\ 2 Department of Physical Education, Guangzhou University, Guangzhou 510006, China; \\ 13795553266@163.com \\ * Correspondence: yima@suse.edu.cn (Y.M.); zhangzhang@suse.edu.cn (H.L.); \\ Tel.: +86-831-598-0214 (Y.M.); +86-831-598-0214 (H.L.) \\ + These authors contributed equally to this work.
}

Received: 12 March 2019; Accepted: 19 April 2019; Published: 23 April 2019

check for updates

\begin{abstract}
This study aimed to investigate the antioxidant activity and release behavior of anthocyanin (ANC) loaded within FA-g-MD wall (ANC-FA-g-MD microcapsule) in vitro. The microencapsulation of ANC was prepared by spray drying and displayed a biphasic release profile. The combination of ANC and FA-g-MD $(0.0625-1 \mathrm{mg} / \mathrm{mL})$ showed a higher antioxidant activity than that of both individuals. A possible intermolecular interaction between ANC and FA-g-MD was studied by UV-vis spectra. Intracellular reactive oxygen species (ROS), 3-(4,5-dimethyl-2-thiazolyl)-2,5-diphenyl-2-H-tetrazolium bromide (MTT) test, and protein expression of quinone oxidoreductase 1(NQO1), glutathione reductase (GSR) and $\gamma$-glutamate cysteine ligase catalytic subunit ( $\gamma$-GCLC) were measured through human colon cancer cells (HT-29). After a 24-hour incubation of the HT-29, the combinations $(0-60 \mu \mathrm{g} / \mathrm{mL})$ exhibited a high potential to diminish the ROS level. And the distinct upregulated expressions of GCLC and NQO1 of HT-29 were detected after treatment with combinations compared to those of single ones. These results suggested that the ANC-FA-g-MD microcapsules exerts enhanced antioxidant effect with capability of the modulation of GCLC and NQO1.
\end{abstract}

Keywords: antioxidant; oxidative stress; anthocyanin; HT-29

\section{Introduction}

Reactive oxygen species (ROS)-induced oxidative stress has been proven to be implicated in the pathogenesis of many diseases, such as diabetes, cardiovascular disease, and various cancer types [1]. Therefore, it is important to modulate the ROS level using some bioactive compounds with capability of resistance to oxidation. [2,3]. Anthocyanin is a natural pigment, commonly existed in many fruits and vegetables, and presented good antioxidant activity potential $[4,5]$. However, the use of anthocyanin as an antioxidant in food is hindered by their vulnerability and poor bioavailability.

So far, many attempts have been made to enhance stability and antioxidant activity of anthocyanins, such as development of delivery systems and multiple antioxidants [6,7]. One approach to enhance bioavailability is microencapsulation. Carbohydrates, protein and their combinations are available for anthocyanin microencapsulation [8-10]. These wall materials present physical barriers to protect anthocyanins from degradation. However, they are not capable of resisting to the oxygen radical 
attack, which may accelerate the degradation of anthocyanins. Just the combination of antioxidants offers an effective alternative to overcome this issue due to their synergistic effect. For example, the multiple antioxidants ( $\beta$-carotene and anthocyanins) were co-encapsulated into $\mathrm{pH}$-responsive microspheres [6]. The multi-functional microspheres showed a synergistic antioxidant activity accompanying by an enhanced thermal stability. Additionally, numerous studies revealed that the combinations of antioxidants show the better antioxidant effects compared to that of single ones [11-14]. However, different characteristics of antioxidants may lead to the complex combination operations and low embedding efficiencies. Thus, it is mandatory to develop a simple, effective and nontoxic delivery system to ensure the bioavailability and antioxidant activity of combinations.

Polysaccharide conjugate, an important encapsulated matrix, provide a good alternative to enhance the antioxidant capacity of ANC [15]. Accordingly, considerable attentions have been paid to develop these functional conjugates. For example, a series of phenolic acids were grafted onto chitosan, starch and cellulose, and their excellent antioxidant properties were correspondingly validated [16-18]. In our former study, we developed several new hydroxycinnamoyl maltodextrin derivatives and their antioxidant activity and cytotoxicity were also evaluated [19]. Among them, maltodextrin-grafted ferulic acid (FA-g-MD) showed the best antioxidant activity. Additionally, we found that anthocyanins encapsulated in maltodextrin-grafted-cinnamic acid can significantly enhance the stability of anthocyanins [19]. Bearing these in mind, FA-g-MD can be used as a potential wall matrix to improve stability of anthocyanins. Nevertheless, further studies are necessary to evaluate release behaviors and antioxidant mechanism of anthocyanins microcapsules. To the best of our knowledge, few studies have been reported in regard to biological activity of a delivery system in cell lines. Recently, Amin et al. constructed anthocyanin loaded (PLGA@PEG) nanoparticle system [7], which largely enhanced the in vitro stability and bioactivity of anthocyanin, that is because PLGA@PEG significantly increased the expression level of several redox-regulated enzymes as compared to the bare anthocyanin-treated group. However, no investigation was performed for the antioxidant effect of a combination of modified polysaccharides and anthocyanin in vitro.

Herein, we aimed to evaluate the enhanced antioxidant activity and release profile of ANC (ANC used, delphindin-3-glucoside) loaded with FA-g-MD in vitro. Thus, we studied release profile of the microparticles and investigated the chemical-scavenging or inhibitory effect of FA-g-MD and ANC on 1,1-diphenyl-2-picrylhydrazyl (DPPH) radicals and lipid peroxidation. In addition, we observed the weak interaction among the antioxidants. Furthermore, the effects of the combination of FA-g-MD and ANC on ROS levels were determined. And the modulation of cellular antioxidant defense was studied for the first time by monitoring protein expression of antioxidant enzymes. This study may present advancement towards the formulation of functional foods with enhanced antioxidant activities.

\section{Results and Discussion}

\subsection{Characterization of Microcapsules}

ANC loaded with FA-g-MD was produced by spray-dried technique. The morphology of the microcapsules was shown in Figure 1. Most of the microcapsules showed plicated spheres, and some cracks and reliefs were also observed. This morphology could be attributed to the collision of the solid granules during the spray-drying process [20]. The diameter of the microcapsules ranged between $2.07 \mu \mathrm{m}$ to $14.85 \mu \mathrm{m}$ with a good dispersity. This observation was previously presented for cinnamic acid-grafted-maltodextrin. The density of the microcapsules were measured to be ranged from 0.571 to $0.587 \mathrm{~g} / \mathrm{cm}^{3}$. And the encapsulation yield (EY) was $51.3 \pm 2.1 \%$, which was due to remain of the prepared FA-g-MD in the spray drier equipment. The value of encapsulation efficiency (EE, calculated using equation in Section 3.4) was $86.3 \pm 2.5 \%$. A similar result was reported in a study on the spray-drying anthocyanins using modified MD as wall matrix [21,22]. In addition, water activity and moisture were $0.30 \pm 0.01$ and $3.47 \pm 0.21 \%$, respectively, which are key factors to maintain food quality. 
These conditions were conducive to the stability of the microcapsules due to less water available in biochemical reactions.

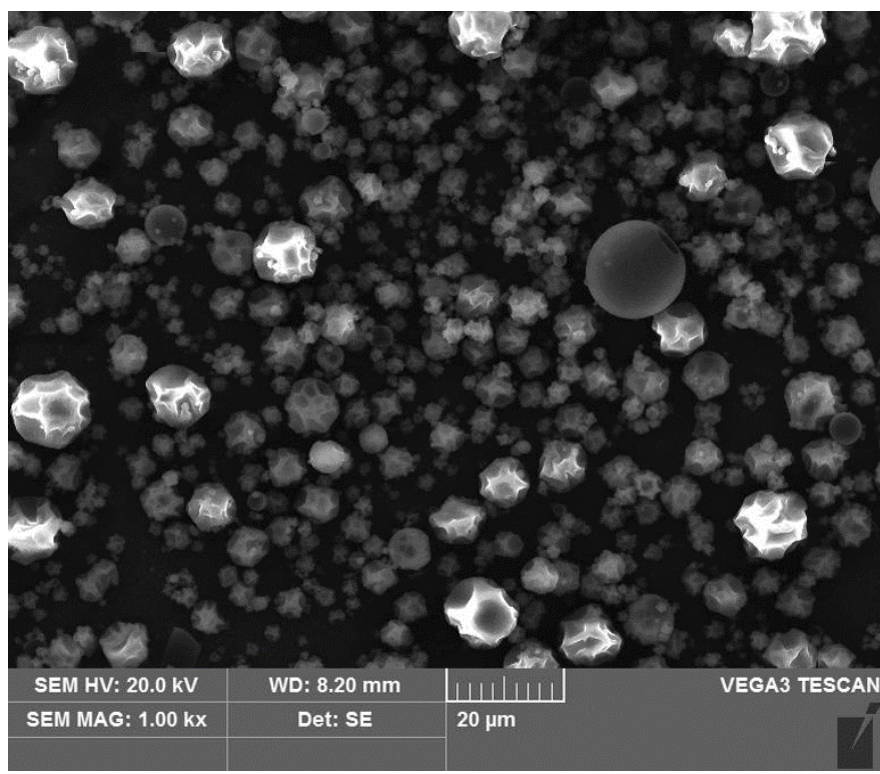

Figure 1. Scanning electron microscope (SEM) images of microcapsules produced by ferulic acid-grafted altodextrin.

\subsection{In Vitro Release Profile of ANC}

To evaluate and compare the release profile of ANC in vitro, the preparations were incubated in simulated gastrointestinal fluid (SGF) and simulated intestinal fluid (SIF). Figure 2 shows the stability of native ANC and the release kinetic from microcapsules. Incubation of these preparations in SGF resulted in an increase of the ANC concentration within the first 20-30 min, and then remained stable for the following $90 \mathrm{~min}$. These results agreed with the release characteristics from the anthocyanin encapsulation systems [23]. It was well known that anthocyanin exists in equilibrium of four molecular species [24]. The high recovery of ANC can be mainly due to the transformation of the colorless chalcone to flavylium cation in gastric environment ( $\mathrm{pH} 1.8$ ). The next section of stomach is the small intestine, which was simulated by SIF. During the SIF incubation, the native ANC degraded sharply. The native ANC concentration decreased to $9.2 \%$ by the end of incubation time. As expected and previously reported, the major difference between SGF and SIF was attributed to the substantially higher $\mathrm{pH}$ of SIF [23]. Compared to the stability of the native ANC, however, the concentration of ANC released from microcapsules increased, indicative of constant release, within the first $20 \mathrm{~min}$. By the end of the incubation time, the ANC concentration declined to $38 \%$. This result indicated that the FA-g-MD microcapsule effectively extended the release of ANC and can be a potential candidate for delivery system of bioactive compounds [7]. 


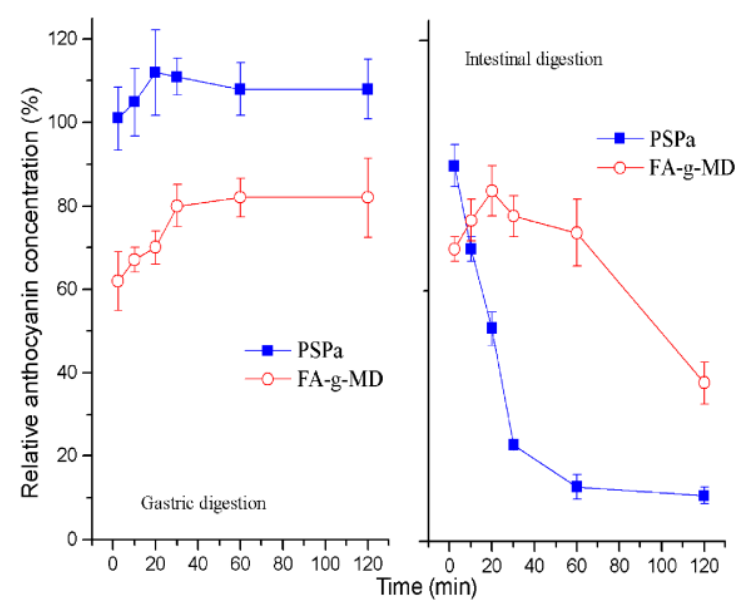

Figure 2. Time-dependent relative anthocyanin concentration in simulated gastric digestion and simulated intestinal digestion after incubation of native ANC and microcapsules produced by FA-g-MD. The values are expressed as mean $\pm \operatorname{SD}(n=3)$.

\subsection{Antioxidant Capacity of ANC, FA-g-MD and Their Combination}

To evaluate the antioxidant potential, two modes of antioxidant action (hydrogen atom transfer and single electron transfer) can be utilized [25]. As shown in Figure 3A, ANC, FA-g-MD and their combination exhibited a concentration-dependent $(0.0625-1 \mathrm{mg} / \mathrm{mL})$ radical-scavenging capacity. Obviously, ANC and FA-g-MD presented good antioxidant activities, as already demonstrated by previous reports [26].These compounds are postulated to have very good electron-donating abilities due to $p-\mathrm{OH}$ and other electron-donating functional groups. The radical-scavenging capacity of the combination $(83 \pm 5.6 \%)$ was significantly higher than that of ANC $(72 \pm 5.7 \%)$ or FA-g-MD $(71 \pm 6.1 \%)$ $(p<0.05)$.
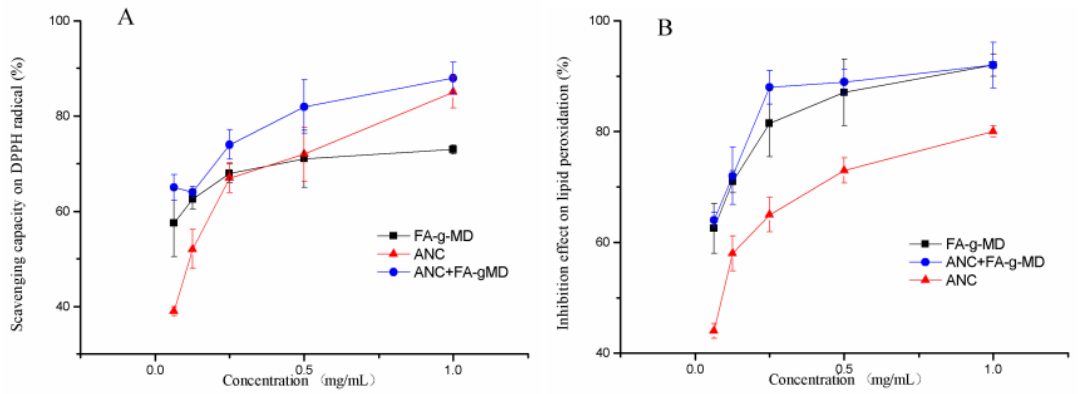

Figure 3. Effects of ANC, FA-g-MD and their combination on inhibiting free radicals. (A) DPPH radicals, (B) lipid peroxidation. The values are expressed as mean $\pm \operatorname{SD}(n=3)$.

Furthermore, a dose-dependent lipid peroxidation inhibition effect was observed in Figure 3B. At a concentration of $0.25 \mathrm{mg} / \mathrm{mL}$, the combination showed significantly higher lipid peroxidation inhibition ability $(89 \pm 2.3 \%)$ than that of ANC $(73 \pm 2.4 \%)$ or FA-g-MD $(86 \pm 6.1 \%)$. The similar observations in antioxidant capacity were also detected among the tested samples in the DPPH assay. The difference of antioxidant activity between ANC and FA-g-MD can be attributed to the position of hydroxyl groups and other features in the chemical structure of ANC and FA-g-MD [27]. Generally, ANC loaded with FA-g-MD showed a stronger antioxidant capability compared to that of ANC.

\subsection{UV-vis Absorption Spectrum of ANC and FA-g-MD}

In order to investigate interaction between ANC and FA-g-MD, UV-vis absorption of ANC and the combination were measured at various concentrations. As shown in Figure 4, ANC had a maximum absorption peak at 533nm, which is the characteristic absorption of anthocyanin [28]. Moreover, 
the combination of ANC and FA-g-MD showed a slight bathochromic shift of $\lambda_{\max }$ as the FA-g-MD concentration increased, which clearly indicated some physically intermolecular interactions [29]. This phenomenon resulted from co-pigmentation effect between ANC and FA-g-MD [30], which may attribute to intermolecular H-bonding or $\pi-\pi$ stacking.

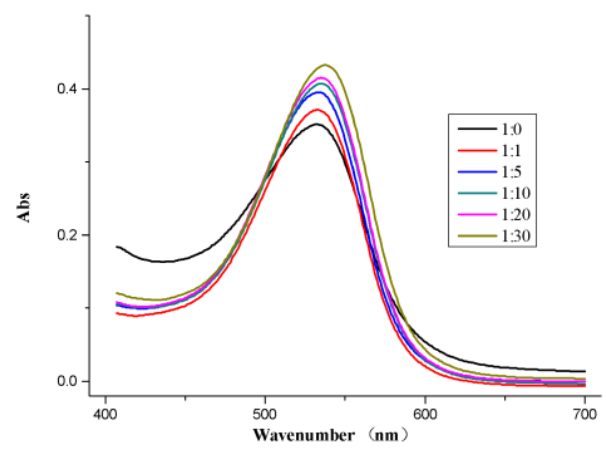

Figure 4. Absorption spectra of ANC $(0.5 \mathrm{mg} / \mathrm{mL})$ in the presence of FA-g-MD in a $\mathrm{pH} 3.5$ citrate buffer with dimethyl sulfoxide (DMSO). ANC/FA-g-MD mass ratio: 1:0, 1:5, 1:10, 1:20, 1:30.

\subsection{Modulation of Cellular ROS Level}

To analyze of the redox effects of the combination of ANC and FA-g-MD in a cellular system, the cellular antioxidant activities (CAA) were first assessed using the dichlorofluorescein (DCF) assay with HT-29 cells. Tested compounds were used at concentrations of $0-100 \mu \mathrm{g} / \mathrm{mL}$, because the samples with these concentrations have been proven to be no toxic toward HT-29 cells (data not shown). The influence of ANC, FA-g-MD and their combination on $\mathrm{H}_{2} \mathrm{O}_{2}$-induced ROS level is shown in Figure 5. Generally, ROS levels were significantly higher in the $\mathrm{H}_{2} \mathrm{O}_{2}$-treated groups than that in the control group, whereas the HT-29 cells in the test compound pre-incubated groups showed lower ROS levels than the positive control (samples treated with $\mathrm{H}_{2} \mathrm{O}_{2}$ only), and the ROS levels in HT-29 group only treated with the samples showed no statistical significances compared with the control group. Obviously, FA-g-MD reduced the ROS levels for all samples. At a concentration of $100 \mu \mathrm{g} / \mathrm{mL}$, FA-g-MD diminished the ROS level down to $70 \%$ of the positive control. A slightly different outcomes were obtained for ANC groups. After 24-h incubation of HT-29 cells, ANC (0-60 $\mu \mathrm{g} / \mathrm{mL})$, diminished ROS level in a concentration-dependent manner. At ANC concentration of $60 \mu \mathrm{g} / \mathrm{mL}$, the fluorescence intensity reduced by $42 \%$ compared to the positive control, which was consistent with previous report [5]. Moreover, the combination exhibited a high potential to diminish the ROS levels and showed significantly higher inhibition potential than FA-g-MD at 0-100 $\mu \mathrm{g} / \mathrm{mL}$. In contrast to the effectiveness of this combination, slight inhibition differences were observed between ANC and the combination at the concentration of 20-60 $\mu \mathrm{g} / \mathrm{mL}$. With treatment at $80-100 \mu \mathrm{g} / \mathrm{mL}$, however, the combination of ANC and FA-g-MD reduced ROS production to a significantly greater extent than ANC did. The highest inhibition by the combination was observed as the reduction down to $48 \%$ at $100 \mu \mathrm{g} / \mathrm{mL}$. Taken together, there was no significant association between chemical (DPPH and lipid peroxidation) and cell-based antioxidant values. In fact, many studies have demonstrated that the differences in the ability of these compounds when incorporated in cells as a requisite for reducing ROS [31,32]. The results suggested that the ANC and FA-g-MD showed ability in the prevention of ROS accumulation. Hence, expression of antioxidant enzymes cannot be ruled out. 


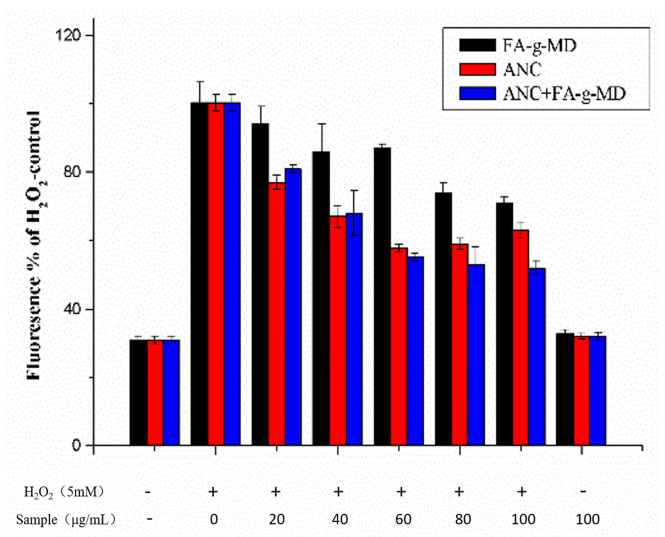

Figure 5. Effects of ANC, FA-g-MD and their combination on reactive oxygen species (ROS) generation. The values are expressed as mean $\pm \operatorname{SD}(n=3)$.

\subsection{Expression of Antioxidant Enzymes}

ROS administration is responsible for enzymatic and non-enzymatic antioxidant systems. A well-known antioxidant transcription factor-Nrf2 has been shown to regulate the expression of these antioxidant enzymes, including NQO1, GCLC and GSR [5,33]. To investigate the mechanism of their enhanced antioxidant activity, the modulation of NQO1, GCLC and GSR protein expression in HT-29 cells (24 h-incubation) was studied using Western blotting. As shown in Figure 6, the antioxidant enzyme expression decreased more significantly in the $\mathrm{H}_{2} \mathrm{O}_{2}$ group than in the control group. In contrast, pre-treatment with ANC, FA-g-MD or their combination resulted in the upregulation of NQO1, GCLC and GSR proteins. Therefore, we hypothesized that antioxidant enzymes affect ANC and/or FA-g-MD mediated protection against $\mathrm{H}_{2} \mathrm{O}_{2}$-induced oxidative stress. When the cells were incubated with the combination, GCLC and NQO1 levels showed a stronger increase $(p<0.05)$. For GCLC, there were increase of $140 \%-180 \%$ with the combination compared with that of ANC or FA-g-MDalone. For NOQ1, the incubation with the mixture of ANC and FA-g-MD caused a marginal increase. Taken together, ANC, FA-g-MD and their combination reversed the $\mathrm{H}_{2} \mathrm{O}_{2}$-induced decrease of GCLC and NQO1 and the combination treatment showed evidently higher upregulation than single treatment, which was in accordance with the changes in ROS levels. We supposed that the enhanced antioxidant activity induced by the combination of ANC and FA-g-MD was due to the upregulated expression of GCLC and NQO1. However, although all treatments were significantly better than that of the $\mathrm{H}_{2} \mathrm{O}_{2}$ group, no enhanced effects were observed in GSR expression of the combination treatment. This result may be related to the biphasic response of GSR to ROS levels. 

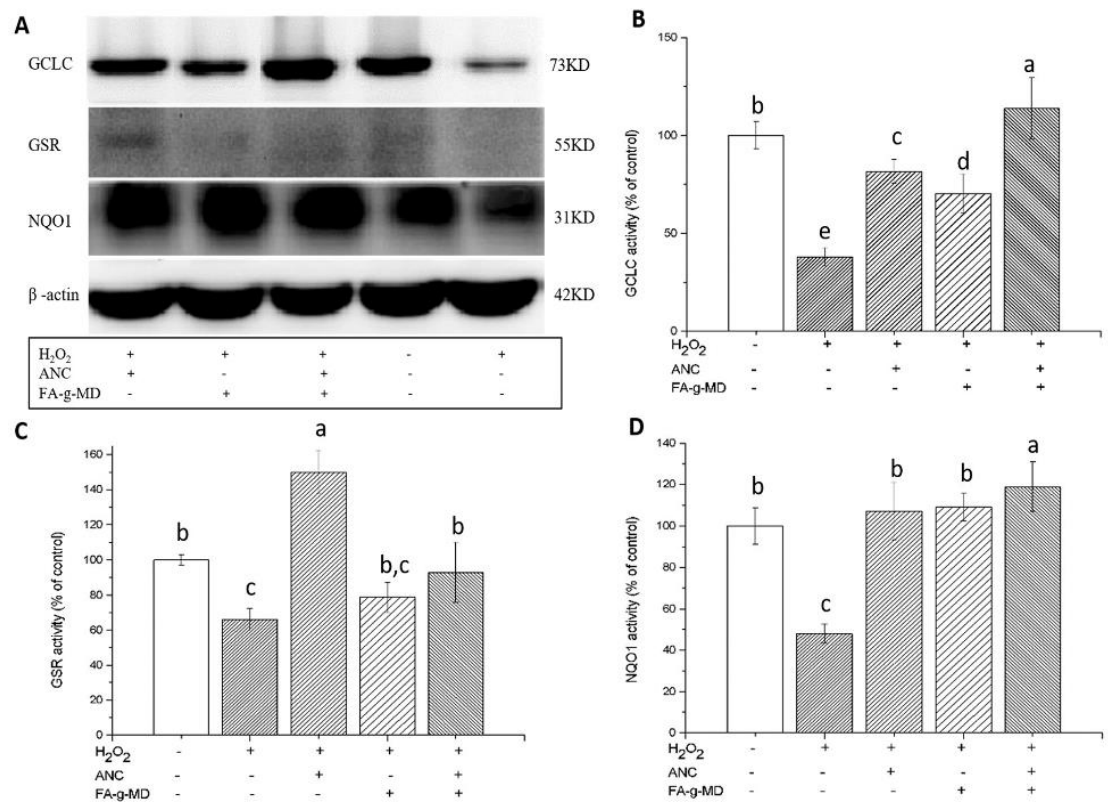

Figure 6. Effects of ANC, FA-g-MD and their combination on the protein expression of GCLC, NQO1, GSR and $\beta$-actin in HT-29. (A) Western blot representative of three enzyme proteins and control. (B-D) The values from densitometry of GCLC, GSR and NQO1 (normalized to the level of $\beta$-actin). The values are expressed as mean $\pm \mathrm{SD}(n=3)$. a-e Mean values with unlike letters were significantly difference.

\section{Materials and Methods}

\subsection{Chemicals, Cells and Media}

Delphinidin-3-glucoside (ANC) was purchased from Ziguang (Nanjing, China). FA-g-MD was prepared by our group. 2,2'-diphenyl-1-picrylhydrazyl radical (DPPH) and 2',7'-dichlorofluorescin diacetate (DCF-DA) were purchased from Aladdin Reagent (Shanghai, China). HT-29 cells were obtained from Chinese Academy of Sciences (Kunming, China). DMEM, DMEM/Nutrient Mix F12 (1:1) medium, fetal bovine serum, penicillin/streptomycin and molecular protein marker were sourced from Invitrogen $\mathrm{GmbH}$ (Karlsruhe, Germany). Cell culture consumable materials were purchased from Greiner Bio-One (Essen, Germany). Monoclonal antibody quinone oxidoreductase 1(NQO1), glutathione reductase (GSR), $\gamma$-glutamatecysteine ligase catalytic submit $(\gamma$-GCLC), and $\beta$-actin mouse monoclonal (IgG1) and secondary antibodies (goat anti-mouse IgG1-HRP, goat anti-rabbit IgG-HRP) were purchased from Santa Cruz Biotechnology (Heidelberg, Germany). All organic solvents and other chemicals were of analytical grade and complied with the standards needed for cell culture experiments.

\subsection{Preparation of Microcapsules}

ANC microcapsules were prepared using spray-drying method [10]. Briefly, FA-g-MD was dissolved in hydroethanol. A $2 \%(w / v)$ total solids dispersion with the ratio of FA-g-MD to ANC of 2:1 was acquired. The ANC aqueous solution was slowly added into the wall matrix solutions. Then, the mixtures were homogenized for $10 \mathrm{~min}$ at 10,000 rpm using an Ultra T25 Basic (IKA, Staufen, Germany). The dispersions were fed into a Mini Spray Drier B-191 (Büchi, Flawil, Switzerland). The inlet and outlet temperature were $129^{\circ} \mathrm{C} \pm 2{ }^{\circ} \mathrm{C}$ and $98^{\circ} \mathrm{C} \pm 2{ }^{\circ} \mathrm{C}$, respectively, with a feed flow of $5 \mathrm{~mL} / \mathrm{min}$ at room temperature. The prepared microcapsules were kept at $4{ }^{\circ} \mathrm{C}$ in a sealed falcon tube to avoid degradation. 


\subsection{Scanning Electron Microscope Analysis (SEM)}

Microcapsules morphology analysis was performed on scanning electron microscope (Tescan Co, Brno, Czech) at an accelerating voltage of $20 \mathrm{KV}$ and magnified up to 5000×. The samples were placed on a double-sided adhesive tape.

\subsection{Encapsulation Yield (EY) and encapsulation efficiency (EE)}

The EY refers to the ratio between the weight of microcapsules and that of all initial solids. And the EE was the ratio between the ANC in the microcapsules $\left(T_{a}\right)$ and the superficial ANC of microcapsules $\left(S_{a}\right)$ [34]. The percentage was calculated as:

$$
E E=\left(1-\frac{S_{a}}{T_{a}}\right) \times 100
$$

where in the $S_{a}$ and $T_{a}$ were determined by absorbance of ANC solution at $523 \mathrm{~nm}$.

\subsection{Volumetric Density}

Volumetric density was measured as previous report [35]. Briefly, $5 \mathrm{~g}$ of ample powder were transferred to a 10-mL graduated cylinder and the cylinder was tapped by hand on a bench 100 times from a height of $10 \mathrm{~cm}$. Then, the bulk density was calculated by dividing the mass of the powder by the final volume occupied by the powder in the cylinder.

\subsection{Moisture Content and Water Activity}

The moisture content was measured in Intelligent Water Activity AM-1 (Huayan, China). The moisture was checked by Rapid Moisture Metre (Hengping, China).

\subsection{In vitro ANC Release}

In vitro release kinetics of ANC from microcapsules were evaluated using a published method [36]. Briefly, samples of both native ANC and ANC-loaded capsules were added $100 \mathrm{~mL}$ of simulated gastric fluid (SGF: $\mathrm{NaCl} 9 \mathrm{~g} / \mathrm{L}$, pepsin $3 \mathrm{~g} / \mathrm{L}$, $\mathrm{pH}$ of 1.8 ) so that the initial total anthocyanin concentration was $0.7 \%$. The solutions were incubated at $37^{\circ} \mathrm{C}$ with continuous vibration.

After a certain time of incubation $(0,10,20,30,60$ and $120 \mathrm{~min}), 1 \mathrm{~mL}$ of solutions were withdrawn and centrifuged at 12,000 rpm for $5 \mathrm{~min}$ at these time points and followed by the corresponding absorbance of supernatants were respectively recorded. Subsequently, the residual samples were added into $100 \mathrm{~mL}$ simulated intestinal fluid (SIF: $\mathrm{NaCl}$ 9g/L, pancreatin $10 \mathrm{~g} / \mathrm{L}$, trysin $10 \mathrm{~g} / \mathrm{L}$, bile salts $3 \mathrm{~g} / \mathrm{L}, \mathrm{pH}$ of 6.5$)$ and incubated at $37^{\circ} \mathrm{C}$ and continuously agitated. At preset time points $(0,10,20$, 30,60 and $120 \mathrm{~min}$ ), the samples were centrifuged at 12,000 rpm for $5 \mathrm{~min}$ to separate the dispersed components. The resulting supernatants were measured as spectrophotometric method.

\subsection{DPPH Radical Scavenging Ability Assay}

DPPH radical scavenging ability of all three samples was evaluated by the method according to the previous report [37]. First, ANC, FA-g-MD and ANC@ FA-g-MD were dissolved into $1.5 \mathrm{~mL}$ DPPH solutions to acquire samples solutions with concentration of 1250, 625, 250, 125 and $62.5 \mu \mathrm{g} / \mathrm{mL}$ respectively. DPPH replaced with DMSO for the above-mentioned solutions were taken as controls. All the sample solutions and controls were allowed to stand at room temperature for 30 minutes. Then, the absorbance of solutions samples and controls at $517 \mathrm{~nm}$ were recorded. Finally, the scavenging effect was defined by the following equation:

$$
\text { Scavenging effect }(\%)=[1-(\text { Asample }- \text { Acontrol }) / \text { Ablank }] \times 100
$$

where $A_{\text {sample }}, A_{\text {blank }}$ and $A_{\text {control }}$ are the absorbance of the sample, blank and control, respectively. 


\subsection{Assay of Lipid Peroxidation Inhibition}

The thiobarbituric acid reactive substances assay was used to determine the lipid peroxidation inhibitory effect according to the previous report [38]. Briefly, the lipid-rich medium was obtained by mixing $1.0 \mathrm{~g}$ of mouse liver and $100 \mathrm{~mL}$ of purified water. And then $1 \mathrm{~mL}$ of liver homogenate, $0.2 \mathrm{~mL}$ of different samples solutions or controls, $50 \mu \mathrm{L}$ of $\mathrm{FeCl}_{2}$ solution $(0.1 \mathrm{mM})$ were uniformly mixed and incubated at $37^{\circ} \mathrm{C}$ for $1 \mathrm{~h}$. Subsequently, $0.3 \mathrm{~mL}$ of trichloroacetic acid $(20 \%, w / v)$ and thiobarbituric acid $(0.8 \%, w / v)$ mixtures were added to terminate the reactions. The resulting solution was incubated at $100{ }^{\circ} \mathrm{C}$ for $15 \mathrm{~min}$ and then centrifuged (6000 rpm, $5 \mathrm{~min}$ ). The absorbance of the supernatant was measured at $532 \mathrm{~nm}$. The inhibitory effect on lipid peroxidation was expressed as the following equation:

$$
\text { Inhibitory effect }(\%)=[1-(\text { Asample }- \text { Acontrol }) / \text { Ablank }] \times 100
$$

where $A_{\text {sample }}, A_{\text {blank }}$ and $A_{\text {control }}$ are the absorbance of the sample, blank and control, respectively.

\subsection{UV-vis Analysis}

All solutions were prepared in a citrate buffer solution $(0.2 \mathrm{M})$ with DMSO at $\mathrm{pH} 3.5$.

Various ANC/FA-g-MD solution samples with ANC/FA-g-MD mass ratios (1:0, 1:1, 1:5, 1:10, 1:20 and 1:30) were prepared by adding ANC $(0.5 \mathrm{mg} / \mathrm{mL})$ into FA-g-MD solutions. Molecular interaction experiments were performed using a UV-vis spectrometer (Puxi, Beijing, China).

\subsection{Cell Culture and Viability Assays}

HT-29 cells were seeded in high-glucose-containing Dulbecco's modified Eagle's medium (DMEM), supplemented with $10 \%$ fetal bovine serum and 100 units/mL of penicillin/streptomycin. The cells were cultured at $37^{\circ} \mathrm{C}$ in humidified $5 \% \mathrm{CO}_{2}$ incubator. Cell viability was assessed by MTT assay [39]. Briefly, HT-29 cells were seeded into a 96-well plate at a density of $2 \times 10^{5}$ cells $/ \mathrm{mL}$ and incubated with ANC, FA-g-MD, or their combination $(1,5,10,50$ and $100 \mu \mathrm{g} / \mathrm{mL})$ for $24 \mathrm{~h}$. Subsequently, the chemical medium was removed, and the cells were placed in the fresh MTT solutions for $4 \mathrm{~h}$ at $37^{\circ} \mathrm{C}$. The optical density was measured at $570 \mathrm{~nm}$ using BMG LAB TECH FLUOstar (GmbH, Offenburg, Germany).

\subsection{ROS Assay}

Oxidative stress in HT-29 cells was assessed using the DCF assay [40]. Briefly, cells were cultured in 96-well plates and cultivated with ANC, FA-g-MD, or their combination for $24 \mathrm{~h}$. After washing with $100 \mu \mathrm{L}$ of PBS, cells were incubated for $30 \mathrm{~min}$ with $50 \mathrm{mM}$ DCF-DA. Then, the treatment medium was removed, and each well was washed with PBS. For the control wells, $100 \mu \mathrm{L}$ of culture medium without $\mathrm{H}_{2} \mathrm{O}_{2}$ was added into the blank wells. Next, $100 \mu \mathrm{L}$ of culture medium containing $5 \mathrm{mM}$ of $\mathrm{H}_{2} \mathrm{O}_{2}$ was added into the other wells [41]. The positive control wells contained the cells treated with DCF-DA and $\mathrm{H}_{2} \mathrm{O}_{2}$ The fluorescence increase (FI) was measured using a fluorescence microplate reader (Multiscan MK3, Thermo, Beijing, China) at 0 and $30 \mathrm{~min}$ (ex/em: 485/528nm). FI was calculated as $\left(\mathrm{F}_{30 \min }-\mathrm{F}_{0 \min }\right) / \mathrm{F}_{0 \min } \times 100$.

\subsection{Protein Expression (Western Blot Analysis)}

Western blotting was performed as previous description [42,43]. All the proteins were collected from cells after treatment. $30 \mu \mathrm{g}$ of protein was electrophoresed on a $10 \%$ SDS-polyacrylamide Tris- $\mathrm{HCl}$ gel (Bio-Rad, Irvine, CA, USA) and electrophoresed at $170 \mathrm{~V}$ for $1 \mathrm{~h}$. The separated proteins were transferred onto a PVDF membrane at $100 \mathrm{~V}$ for $30 \mathrm{~min}$ on ice. After the transfer, membranes were blocked at room temperature for $1 \mathrm{~h}$ in $1 \times$ TBST containing 5\% non-fat dry milk. The membrane was probed with primary antibodies (NQO1, $\gamma$-GCLC, GSR and $\beta$-actin). The signal bands were visualized using enhanced chemiluminescence (Bio-Rad, USA). 


\subsection{Statistical Analysis}

Data were expressed as means \pm SD. Statistical differences were analyzed using one-way analysis of variance (ANOVA) by IBM SPSS Statistics 20 . The differences were considered to be statistically significant when $p<0.05$.

\section{Conclusions}

To improve the stability and antioxidant activity of ANC, FA-g-MD microcapsules were investigated. These microcapsules effectively extended the release of ANC. Our results have also demonstrated that the combination of ANC and FA-g-MD provided more enhanced antioxidant activity than each alone by scavenging DPPH radical and inhibiting lipid peroxidation directly, diminishing ROS and regulating the antioxidant enzymes. Additionally, the combination function can mainly contribute to the upregulation of GCLC and NQO1. Thus, we assumed that ANC coated with FA-g-MD could be a new antioxidant in the field of manufacturing functional foods to prevent oxidative stress damages.

Author Contributions: Y.M., Y.F. and H.L. designed research; Y.F., W.Z. and Y.M. performed research; Y.M., and Y.F. analyzed the data and wrote the paper; H.L. supervised the project.

Acknowledgments: This work was supported by National Natural Science Foundation of China (31801458), Talent introduction program of Sichuan University of science and engineering (2017RCL24), Education department of Sichuan province (16ZB0248), Solid-state Fermentation Resource Utilization Key Laboratory of Sichuan Province (2016GTJ004), Liquor making biology technology and application of Key Laboratory Program of Sichuan Province, China (NJ2017-04).

Conflicts of Interest: The authors declare no conflict of interest.

\section{Abbreviations}

$\begin{array}{ll}\text { ANC } & \text { Anthocyanin } \\ \text { FA-g-MD } & \text { Ferulic acid-grafted-maltodextrin } \\ \text { ROS } & \text { Reactive oxygen species } \\ \text { DPPH } & 2,2^{\prime} \text {-diphenyl-1-picrylhydrazyl radical } \\ \text { DCF-DA } & 2^{\prime}, 7^{\prime} \text {-dichlorofluorescin diacetate } \\ \text { NQO1 } & \text { quinone oxidoreductase } 1 \\ \text { GSR } & \text { glutathione reductase } \\ \gamma \text {-GCLC } & \gamma \text {-glutamate cysteine ligase catalytic subunit }\end{array}$

\section{References}

1. Schieber, M.; Chandel, N.S. ROS Function in Redox Signaling and Oxidative Stress. Current Biol. 2014, 24 , R453-R462. [CrossRef]

2. Myung, S.-K.; Ju, W.; Cho, B.; Oh, S.-W.; Park, S.M.; Koo, B.-K.; Park, B.-J. Efficacy of vitamin and antioxidant supplements in prevention of cardiovascular disease: Systematic review and meta-analysis of randomised controlled trials. BMJ Brit. Med. J. 2013, 346, f10. [CrossRef]

3. Aruoma, O.I. Antioxidant actions of plant foods: Use of oxidative DNA damage as a tool for studying antioxidant efficacy. Free Radical Res. 2009, 30, 419-427. [CrossRef]

4. Diaconeasa, Z.; Leopold, L.; Rugină, D.; Ayvaz, H.; Socaciu, C. Antiproliferative and Antioxidant Properties of Anthocyanin Rich Extracts from Blueberry and Blackcurrant Juice. Int. J. Mol. Sci. 2015, 16, 2352-2365. [CrossRef]

5. Jing, P.; Qian, B.; Zhao, S.; Qi, X.; Ye, L.; Giusti, M.M.; Wang, X. Effect of glycosylation patterns of Chinese eggplant anthocyanins and other derivatives on antioxidant effectiveness in human colon cell lines. Food Chem. 2015, 172, 183-189. [CrossRef]

6. Shi, M.; Bai, J.; Zhao, L.; Yu, X.; Liang, J.; Liu, Y.; Nord, W.; Li, Y. Co-loading and intestine-specific delivery of multiple antioxidants in $\mathrm{pH}$-responsive microspheres based on TEMPO-oxidized polysaccharides. Carbohyd. Polym. 2017, 157, 858-8657. [CrossRef] [PubMed] 
7. Amin, F.U.; Shah, S.A.; Badshah, H.; Khan, M.; Kim, M.O. Anthocyanins encapsulated b PLGA@PEG nanoparticles potentially improved its free radical scavenging capabilities via p38/JNK pathway against A $31-42-$ induced oxidative stress. J. Nanobiotech. 2017, 15, 12-28. [CrossRef] [PubMed]

8. Tan, L.H.; Chan, L.W.; Heng, P.W.S. Alginate/starch composites as wall material to achieve microencapsulation with high oil loading. J. Microencapsul. 2008, 26, 263-271. [CrossRef] [PubMed]

9. Mahdavi, S.A.; Jafari, S.M.; Ghorbani, M.; Assadpoor, E. Spray-Drying Microencapsulation of Anthocyanins by Natural Biopolymers: A Review. Dry. Technol. 2014, 32, 509-518. [CrossRef]

10. Davidov-Pardo, G.; Arozarena, I.; Marín-Arroyo, M.R. Optimization of a Wall Material Formulation to Microencapsulate a Grape Seed Extract Using a Mixture Design of Experiments. Food Bioprocess Tech. 2012, 6, 941-951. [CrossRef]

11. Bai, H.; Liu, R.; Chen, H.L.; Zhang, W.; Wang, X.; Zhang, X.D.; Li, W.L.; Hai, C.X. Enhanced antioxidant effect of caffeic acid phenethyl ester and Trolox in combination against radiation induced-oxidative stress. Chem. Biol. Interact. 2014, 207, 7-15. [CrossRef]

12. Chu, C.; Lu, F.J.; Yeh, R.H.; Li, Z.L.; Chen, C.H. Synergistic antioxidant activity of resveratrol with genistein in high-glucose treated Madin-Darby canine kidney epithelial cells. Biomed. Rep. 2016, 4, 349-354. [CrossRef] [PubMed]

13. Pantan, R.; Tocharus, J.; Suksamrarn, A.; Tocharus, C. Synergistic effect of atorvastatin and Cyanidin-3-glucoside on angiotensin II-induced inflammation in vascular smooth muscle cells. Exp. Cell Res. 2016, 342, 104-112. [CrossRef]

14. Sharif, H.R.; Goff, H.D.; Majeed, H.; Shamoon, M.; Liu, F.; Nsor-Atindana, J.; Haider, J.; Liang, R.; Zhong, F. Physicochemical properties of $\beta$-carotene and eugenol co-encapsulated flax seed oil powders using OSA starches as wall material. Food Hydrocolloids 2017, 73 (Supp. C), 274-283. [CrossRef]

15. Aewsiri, T.; Benjakul, S.; Visessanguan, W.; Eun, J.-B.; Wierenga, P.A.; Gruppen, H. Antioxidative activity and emulsifying properties of cuttlefish skin gelatin modified by oxidised phenolic compounds. Food Chem. 2009, 117, 160-168. [CrossRef]

16. Mathew, S.; Abraham, T.E. Characterisation of ferulic acid incorporated starch-chitosan blend films. Food Hydrocolloid. 2008, 22, 826-835. [CrossRef]

17. Wrigstedt, P.; Kylli, P.; Pitkanen, L.; Nousiainen, P.; Tenkanen, M.; Sipila, J. Synthesis and antioxidant activity of hydroxycinnamic acid xylan esters. J. Agric. Food Chem. 2010, 58, 6937-6943. [CrossRef] [PubMed]

18. Woranuch, S.; Yoksan, R.; Akashi, M. Ferulic acid-coupled chitosan: Thermal stability and utilization as an antioxidant for biodegradable active packaging film. Carbohyd. Polym. 2015, 115, 744-751. [CrossRef] [PubMed]

19. Ma, Y.; Hou, C.-J.; Fa, H.-B.; Huo, D.-Q.; Yang, M. Synthesis and antioxidant property of hydroxycinnamoyl maltodextrin derivatives. Int. J. Food Sci. Technol. 2016, 51, 2450-2459. [CrossRef]

20. García-Tejeda, Y.V.; Salinas-Moreno, Y.; Martínez-Bustos, F. Acetylation of normal and waxy maize starches as encapsulating agents for maize anthocyanins microencapsulation. Food Bioprod. Process. 2015, 94, 717-726. [CrossRef]

21. Ah med, M.; Akter, M.S.; Lee, J.C.; Eun, J.B. Encapsulation by spray drying of bioactive components, physicochemical and morphological properties from purple sweet potato. LWT-Food Sci. Technol. 2010, 43, 1309-1322.

22. Ma, Y.; Hou, C.-J.; Wu, H.-X.; Fa, H.-B.; Li, J.-J.; Shen, C.-H.; Li, D.; Huo, D.-Q. Synthesis of maltodextrin-grafted-cinnamic acid and evaluation on its ability to stabilize anthocyanins via microencapsulation. J. Microencapsul. 2016, 33, 554-562. [CrossRef]

23. Oidtmann, J.; Schantz, M.; Mader, K.; Baum, M.; Berg, S.; Betz, M.; Kulozik, U.; Leick, S.; Rehage, H.; Schwarz, K.; et al. Preparation and comparative release characteristics of three anthocyanin encapsulation systems. J. Agric. Food Chem. 2012, 60, 844-851. [CrossRef] [PubMed]

24. Gomes, R.; Parola, A.J.; Lima, J.C.; Pina, F. Solvent effects on the thermal and photochemical reactions of 4'-iodo-8-methoxyflavylium and their consequences on the coloring phenomena caused by anthocyanins in plants. Chemistry-Eur. J. 2006, 12, 7906-7912. [CrossRef]

25. Huang, D.; Ou, B.; Prior, R.L. The Chemistry behind Antioxidant Capacity Assays. J. Agric. Food Chem. 2005, 53, 1841-1856. [CrossRef]

26. Szelag, M.; Urbaniak, A.; Bluyssen, H.A.R. A theoretical antioxidant pharmacophore for natural hydroxycinnamic acids. Open Chem. 2015, 13. [CrossRef] 
27. Kylli, P.; Nousiainen, P.; Biely, P.; SIPILÄ, J.; Tenkanen, M.; Heinonen, M. Antioxidant Potential of Hydroxycinnamic Acid. J. Agric. Food Chem. 2008, 56, 4797-4805. [CrossRef]

28. Rustioni, L.; Di Meo, F.; Guillaume, M.; Failla, O.; Trouillas, P. Tuning color variation in grape anthocyanins at the molecular scale. Food Chem. 2013, 141, 4349-4357. [CrossRef]

29. Sousa, A.; Araujo, P.; Cruz, L.; Bras, N.F.; Mateus, N.; De Freitas, V. Evidence for copigmentation interactions between deoxyanthocyanidin derivatives (oaklins) and common copigments in wine model solutions. J. Agric. Food Chem. 2014, 62, 6995-7001. [CrossRef]

30. Stephanie, G.; Nathalie, M.; Abert-Vian, M.; Njara, R.; Dangles, O. Chemical Synthesis of Hydroxycinnamic Acid Glucosides and Evaluation of Their Ability To Stabilize Natural Colors via Anthocyanin Copigmentation. J. Agric. Food Chem. 2007, 55, 7573-7579.

31. Wolfe, K.L.; Liu, R.H. Structure-activity relationships of flavonoids in the cellular antioxidant activity assay. J. Agric. Food Chem. 2008, 56, 8404-8411. [CrossRef] [PubMed]

32. Wolfe, K.L.; Liu, R.H. Cellular Antioxidant Activity (CAA) Assay for Assessing Antioxidants Foods and Dietary Supplements. J. Agric. Food Chem. 2007, 55, 8896-8907. [CrossRef]

33. Bakuradze, T.; Lang, R.; Hofmann, T.; Stiebitz, H.; Bytof, G.; Lantz, I.; Baum, M.; Eisenbrand, G.; Janzowski, C. Antioxidant effectiveness of coffee extracts and selected constituents in cell-free systems and human colon cell lines. Mol. Nutr. Food Res. 2010, 54, 1734-1743. [CrossRef] [PubMed]

34. Zhang, L.; Mou, D.; Du, Y. Procyanidins: Extraction and micro- encapsulation. J. Sci. Food. Agr. 2007, 87, 2192-2197. [CrossRef]

35. Santiago-Adame, R.; Medina-Torres, L.; Gallegos-Infante, J.A.; Calderas, F.; Gonzalez-Laredo, R.F.; Rocha-Guzman, N.E.; Ochoa-Martínez, L.A.; Bernad-Bernad, M.J. Spray drying-microencapsulation of cinnamon infusions(Cinnamomum zeylanicum) with maltodextrin. LWT-Food Sci. Technol. 2015, 64, 571-577. [CrossRef]

36. Tulini, F.L.; Souza, V.B.; Thomazini, M.; Silva, M.P.; Massarioli, A.P.; Alencar, S.M.; Pallone, E.M.J.A.; Genovese, M.I.; Favaro-Trindade, C.S. Evaluation of the release profile, stability andantioxidant activity proanthocyanidin-rich cinnamon (Cinnamomum zeylanicum) extract co-encapsulated with $\alpha$-tocopherol by spray chilling. Food Res. Int. 2017, 95, 117-124. [CrossRef]

37. Kahkonen, M.P.; Heinonen, M. Antioxidant activity of anthocyanins and their aglycons. J. Agric. Food Chem. 2003, 51, 628-633. [CrossRef] [PubMed]

38. Xie, M.; Hu, B.; Wang, Y.; Zeng, X. Grafting of gallic acid onto chitosan enhances antioxidant activities and alters rheological properties of the copolymer. J. Agric. Food Chem. 2014, 62, 9128-9136. [CrossRef]

39. Soenen, S.J.; Himmelreich, U.; Nuytten, N.; De Cuyper, M. Cytotoxic effects of iron oxide nanoparticles and implications for safety in cell labelling. Biomaterials 2011, 32, 195-205. [CrossRef] [PubMed]

40. Wang, H.; Joseph, J.A. Quantifying cellular oxidative stress by dichlorofluorescein assay using microplate reader11Mention of a trade name, proprietary product, or specific equipment does not constitute a guarantee by the United States Department of Agriculture and does not imply its approval to the exclusion of other products that may be suitable. Free Radical Bio. Med. 1999, 27, 612-616.

41. Cilla, A.; Laparra, J.M.; Alegria, A.; Barbera, R.; Farre, R. Antioxidant effect derived from bioaccessible fractions of fruit beverages against H2O2-induced oxidative stress in Caco-2 cells. Food Chem. 2008, 106, 1180-1187. [CrossRef]

42. Bellion, P.; Olk, M.; Will, F.; Dietrich, H.; Baum, M.; Eisenbrand, G.; Janzowski, C. Formation of hydrogen peroxide in cell culture media by apple polyphenols and its effect on antioxidant biomarkers in the colon cell line HT-29. Mol. Nutr. Food Res. 2009, 53, 1226-1236. [CrossRef] [PubMed]

43. Wang, X.; Kingsley, P.J.; Marnett, L.J.; Eling, T.E. The Role of NAG-1/GDF15 in the Inhibition of Intestinal Polyps in APC/Min Mice by Sulindac. Cancer Prev. Res. 2011, 4, 150. [CrossRef] [PubMed]

Sample Availability: Samples of the compounds are not available from the authors. 